\title{
ARBORIZATION BLOCK
}

\author{
F. A. WILLIUS, M.D. \\ Mayo Clinic, Rochester, Minn.
}

Arborization block or impaired intraventricular conduction is dependent on graphic records for its recognition. It is now generally accepted to indicate disease of the subendocardial myocardium ${ }^{1}$ and evidences serious functional cardiac disturbance. ${ }^{2}$ The involvement occurs in the subendocardial or Purkinje plexus.

The deflections constituting the initial ventricular complex of the electocardiogram are termed $\mathrm{Q}, \mathrm{R}, \mathrm{S}$, and indicate the passage of the electrical impulse through the main divisions of the auriculoventricular bundle and their arborizations. These deflections comprise a graphic record which is upright in all leads, is abruptly pointed, and has a narrow base. The normal base width does not exceed 0.10 second. ${ }^{3}$

Arborization block is recognized by abnormal deviations of the $Q, R, S$ group. These are increased width, notching of the apex, and splintering of the ascending and descending limbs.

The bizarre complex of arborization block is probably due either to impulse transmission through circuitous and aberrant paths or to delayed transmission through normal channels. Experimental and clinical evidence supports the former view. The abnormal complex, constituting the ventricular premature contraction (extrasystole), is well recognized, as is the complex of ventricular tachycardia and the idioventricular complex of complete auriculoventricular dissociation, which simulate the notched and widened $Q, R, S$ group of arborization block. These we know result from ectopic stimuli which arise somewhere in the ventricular musculature and traverse aberrant paths to provoke ventricular systoles. The constancy in form of the deflections of the normal electrocardiogram make the abnormal complexes stand out as striking entities.

The present study was undertaken to determine, if possible, the significance of this disordered mechanism with especial reference to life expectancy.

1. Carter, E. P.: Further Observations on the Aberrant Electrocardiogram Associated with Sclerosis of the Atrioventricular Bundle Branches and Their Terminal Arborizations, Arch. Int. Med. 22:331, 1918.

1. Oppenheimer, B. S., and Rothschild, M. A.: Electrocardiographic Changes Associated with Myocardial Involvement. J. A. M. A. 69:429, 1917.

2. Robinson, G. C.: The Relation of Changes in the Form of the Ventricular complex of the Electrocardiogram to Functional changes in the Heart, Arch. Int. Med. 18:830, 1916.

3. Lewis, T.: Clinical Electrocardiography, London. Shaw, 1913, p. 32. 
One hundred and thirty-eight patients with arborization block have been examined. The electrocardiographic requirements warranting this diagnosis were, (1) notching of the apex $R$, (2) splintering of the ascending or descending limb, and (3) in complexes of normal contour, a base width exceeding 0.10 second. These changes are summarized in Table 1.

The electrocardiograms illustrate the types represented (Figs. 1 to 10). The tension of the galvanometer fiber influences the width of the unaltered complex; a loose fiber is capable of giving an increased base width. ${ }^{4}$

The disorders responsible for the development of subendocardial myocardial disease are, (1) infections, (2) degenerative processes, and (3) local nutritional disturbances. These observations are summarized in Table 2.

TABLE 1.-Q, R, S-

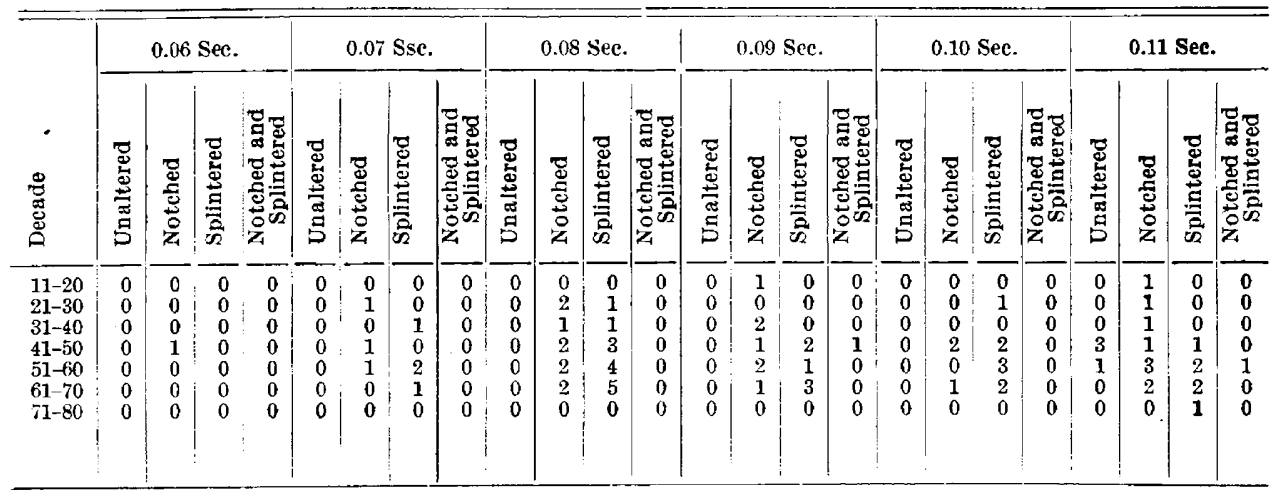

Endocarditis was the most frequent causative disorder, and occurred in forty-nine of the 138 cases ( 35.5 per cent.). Its predominance in the earlier decades of life was anticipated; degenerative and local nutritional disturbances dominate the later decades. In order of frequency are cardiovascular-renal disease with hypertension, thyrotoxic adenomas and arteriosclerosis. Exophthalmic goiter occurred in five cases. Only four proved cases of lues were found. In twenty-seven instances no tangible histories or findings suggesting causative factors were obtained.

Exertion dyspnea was a complaint in all cases, and in thirty-one (22.5 per cent.) orthopnea was a dominant symptom. Palpitation on exertion was present in forty-seven instances ( 34 per cent.). Twentytwo patients ( 15.9 per cent.) had angina pectoris and in five of these this occurred in aortic disease. Edema of the lower extremities varying

4. Hirschfelder, A. D.: Personal communication to the author. 
from slight pitting in most instances to definite swelling with glazed skin in a smaller number, was present in forty-two patients (30.4 per cent.). Only five cases of general anasarca are recorded in this series. Of the edema cases twenty-four (57.1 per cent.) occurred in patients with endocardial valvular disease. The relative infrequency of edema in grave heart disease is very interesting, and emphasizes the importance of adjunct methods in the thorough examination of patients suffering from cardiac disease.

Objectively, the striking feature present in practically all of the cases is the lack of definition of the heart sounds. They are muffled, the normal differentiation between the first and second sounds is absent, and the auscultatory findings of embryocardia are simulated. There was an increase in cardiac dulness in most of our cases, both to the right and to the left of the midsternal line. Auricular fibrilla-

-Complex Changes

\begin{tabular}{|c|c|c|c|c|c|c|c|c|c|c|c|c|c|c|c|c|c|c|c|c|c|c|c|c|c|c|c|c|}
\hline \multicolumn{4}{|c|}{0.12 Sec. } & \multicolumn{4}{|c|}{0.13 Sec. } & \multicolumn{4}{|c|}{0.14 Sec. } & \multicolumn{4}{|c|}{0.15 Sec. } & \multicolumn{4}{|c|}{0.16 Sec. } & \multicolumn{4}{|c|}{0.17 See. } & \multicolumn{4}{|c|}{0.18 Sec. } & \multirow[b]{2}{*}{ | } \\
\hline 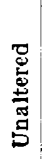 & 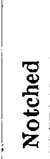 & 总 & 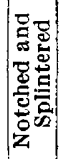 & 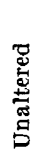 & 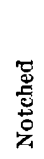 & 总 & 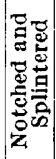 & 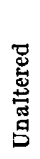 & $\begin{array}{l}\frac{D}{d} \\
\frac{\vec{g}}{\mathrm{~d}} \\
\frac{0}{2}\end{array}$ & 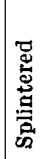 & 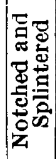 & 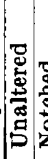 & 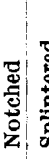 & 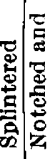 & 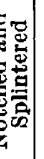 & 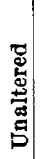 & 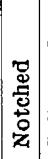 & 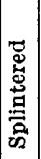 & 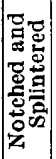 & 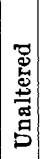 & 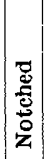 & 总 & 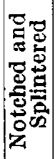 & 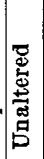 & 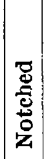 & 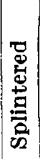 & 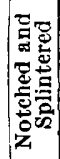 & \\
\hline $\begin{array}{l}0 \\
0 \\
1 \\
2 \\
1 \\
0 \\
0\end{array}$ & $\begin{array}{l}0 \\
2 \\
1 \\
3 \\
5 \\
4 \\
1\end{array}$ & $\begin{array}{l}0 \\
0 \\
0 \\
2 \\
2 \\
4 \\
2\end{array}$ & $\begin{array}{l}0 \\
1 \\
0 \\
1 \\
1 \\
0 \\
1\end{array}$ & $\begin{array}{l}0 \\
0 \\
0 \\
0 \\
0 \\
0 \\
0\end{array}$ & $\begin{array}{l}0 \\
0 \\
0 \\
1 \\
0 \\
0 \\
0\end{array}$ & $\begin{array}{l}0 \\
1 \\
0 \\
0 \\
1 \\
0 \\
1\end{array}$ & $\begin{array}{l}0 \\
0 \\
0 \\
0 \\
2 \\
0 \\
0\end{array}$ & $\begin{array}{l}0 \\
0 \\
0 \\
0 \\
0 \\
0 \\
0\end{array}$ & $\begin{array}{l}0 \\
0 \\
0 \\
0 \\
3 \\
2 \\
1\end{array}$ & $\begin{array}{l}0 \\
0 \\
0 \\
0 \\
0 \\
1 \\
0\end{array}$ & $\begin{array}{l}0 \\
0 \\
0 \\
0 \\
0 \\
3 \\
0\end{array}$ & \begin{tabular}{l|l}
0 \\
0 \\
0 \\
0 \\
0 \\
0 \\
0
\end{tabular} & $\begin{array}{ll}0 & 0 \\
0 & 0 \\
0 & 0 \\
0 & 0 \\
0 & 0 \\
1 & 0 \\
0 & 0\end{array}$ & $\begin{array}{l}0 \\
0 \\
0 \\
0 \\
0 \\
0 \\
0\end{array}$ & $\begin{array}{l}0 \\
0 \\
0 \\
0 \\
0 \\
0 \\
0\end{array}$ & $\begin{array}{l}0 \\
0 \\
0 \\
0 \\
0 \\
0 \\
0\end{array}$ & $\begin{array}{l}0 \\
0 \\
0 \\
0 \\
0 \\
2 \\
0\end{array}$ & $\begin{array}{l}0 \\
0 \\
0 \\
0 \\
2 \\
1 \\
0\end{array}$ & $\begin{array}{l}0 \\
0 \\
1 \\
2 \\
1 \\
0\end{array}$ & $\begin{array}{l}0 \\
0 \\
0 \\
0 \\
0 \\
0 \\
0\end{array}$ & $\begin{array}{l}0 \\
0 \\
0 \\
1 \\
0 \\
0 \\
0\end{array}$ & $\begin{array}{l}0 \\
0 \\
0 \\
0 \\
0 \\
0 \\
0\end{array}$ & $\begin{array}{l}0 \\
0 \\
0 \\
0 \\
0 \\
0 \\
0\end{array}$ & $\begin{array}{l}0 \\
0 \\
0 \\
0 \\
0 \\
0 \\
0\end{array}$ & $\begin{array}{l}0 \\
0 \\
0 \\
0 \\
0 \\
0 \\
0\end{array}$ & $\begin{array}{l}0 \\
0 \\
0 \\
0 \\
0 \\
0 \\
0\end{array}$ & $\begin{array}{l}0 \\
0 \\
0 \\
0 \\
0 \\
1 \\
0\end{array}$ & $\begin{array}{r}2 \\
10 \\
8 \\
31 \\
41 \\
39 \\
7\end{array}$ \\
\hline
\end{tabular}

tion was present in eighteen cases ( 13 per cent.), and occurred except in one instance in the later decades of life. Four patients had delayed auriculoventricular conduction, that is $\mathrm{P}-\mathrm{R}$ intervals exceeding 0.22 second. The deflection amplitudes of the $Q, R, S$ group showed that sixty-four patients (46.4 per cent.) had normal values (10 to 15 millivolts), sixty-one patients ( 44.2 per cent.) had high values, the greatest 39 millivolts, and thirteen patients (9.4 per cent.) had low values, the lowest of which was 5 millivolts. Deflections of high amplitude, largely diphasic, are believed by Carter to be indicative of a definite, totally obstructive, temporary or permanent lesion of one of the branches of the auriculoventricular bundle; those of low amplitude suggest diffuse sclerosis, although they do not preclude localized lesions of the main branch and its arborizations.

No striking changes in amplitude of the final $T$-wave of the ventricular complex were noted. This wave was negative in eighty-five 
cases (63 per cent.), and occurred most frequently in Lead 1 alone, in forty-two cases (49.4 per cent.). Table 3 shows the $T$-wave negatively in this series. The inversion of the $T$-wave in Lead 1 is significant, I believe, and of itself indicative of myocardial changes, for in all the electrocardiograms studied in which this observation was noted,

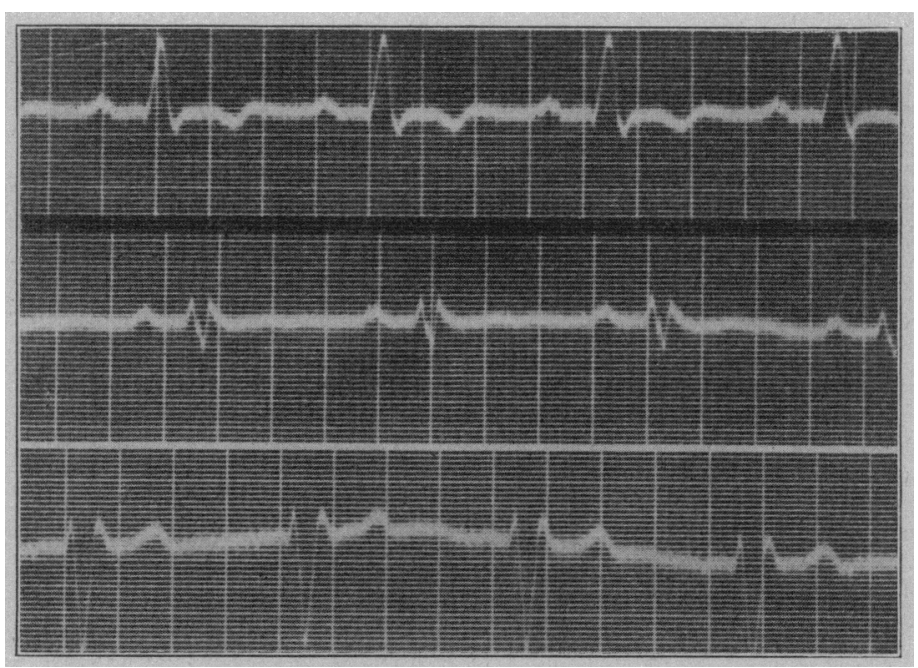

Fig. 1.-Rate 65. Q. R, S complex widened in Leads 1 and $30.11 \mathrm{sec}$. and splintered in Lead 2. Inverted T-wave, Lead 1. Left ventricular preponderince. Case 160997.

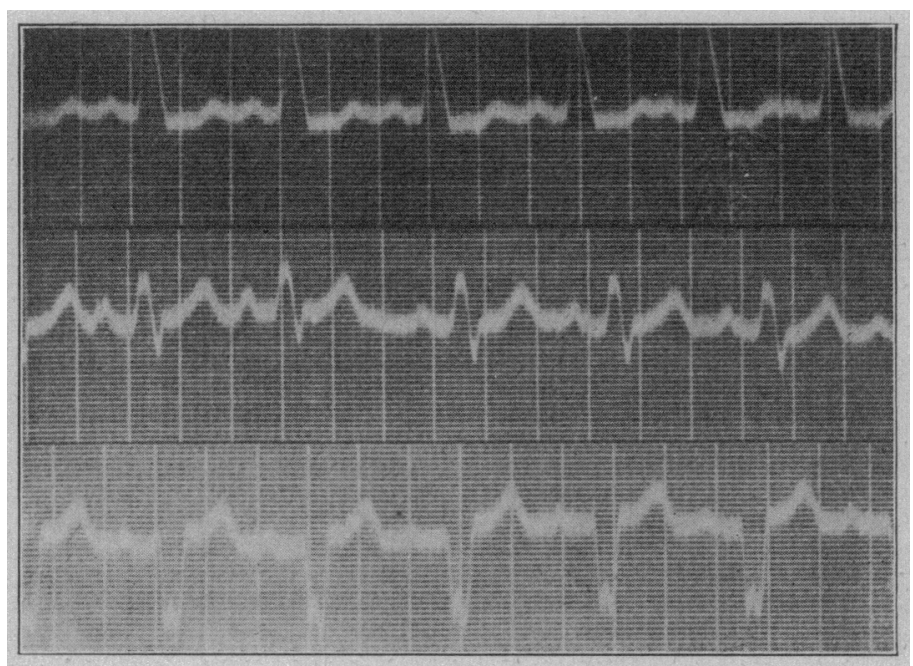

Fig. 2.-Rate 100. Q, R, S complex notched and widened $0.12 \mathrm{sec}$. Left ventricular preponderance. Case 213193. 
the patients presented definite clinical evidence of myocardial insufficiency, except in one case, in which the conclusions were indefinite.

One hundred and twelve patients with arborization block have been heard from in answer to letters of inquiry. Seventy-eight (69.6 per cent.) of these have died; all except three died of heart disease. the average duration of life from the time of examination was eight

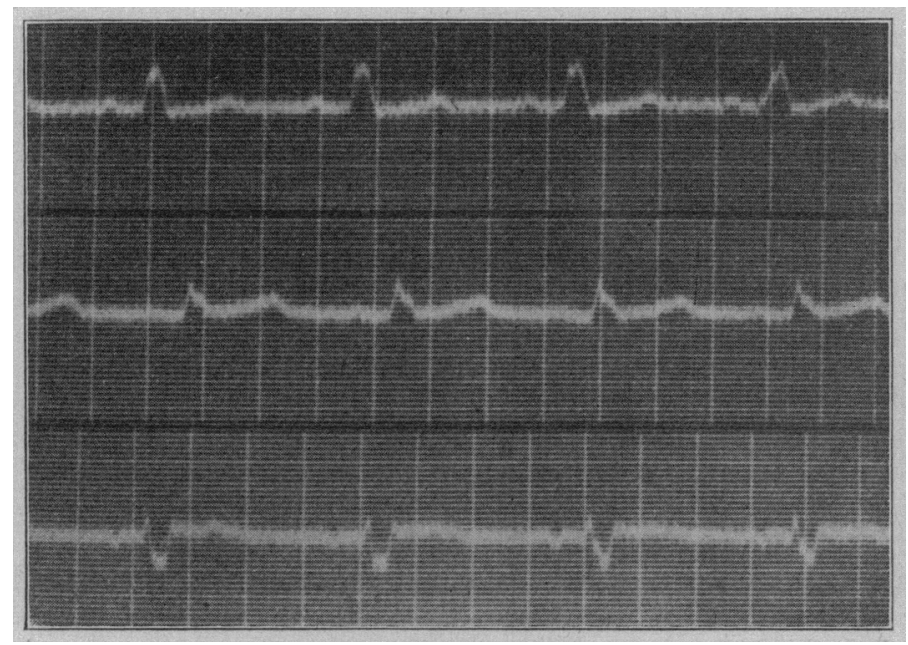

Fig. 3-Rate 60. Q. R, S complex notched. Left ventricular preponderance. Case 154767.

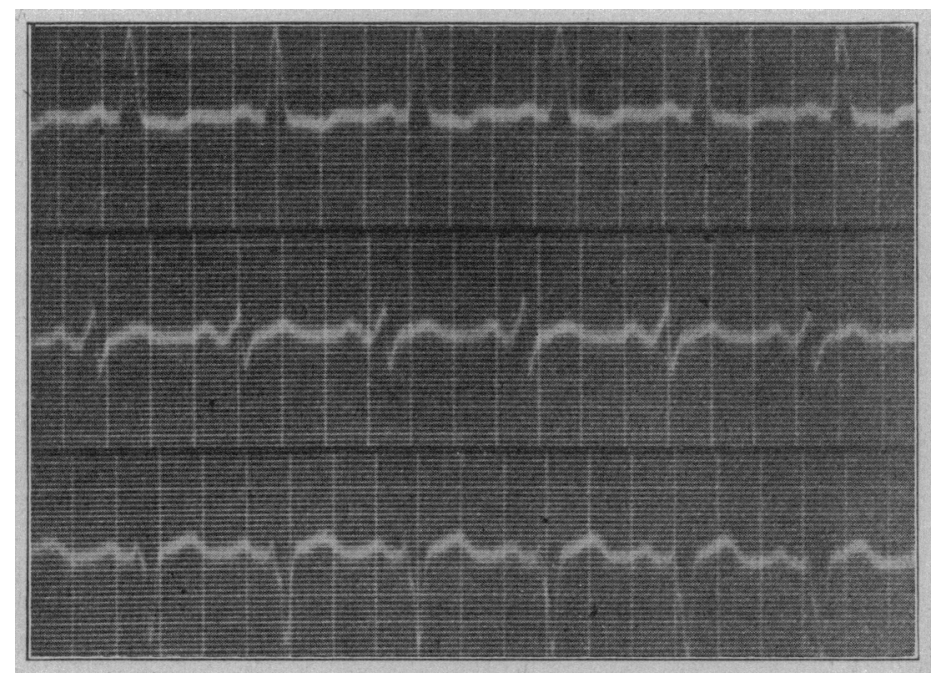

Fig. 4.- Rate 82. Q, R. S complex splintered and widened 0.11 sec. Left ventricular preponderance. Case 165664. 
and one-half months. These statistics bear out the presumption that arborization block is a grave disorder. It is well recognized that disease involving the conduction system is a serious menace to life, but arborization block is attended by an earlier mortality than that caused by the lesions higher up. As life is directly dependent on ventricular action, any impairment of ventricular function is grave. The deaths are summarized in Table 4.

Thirty-four patients of the series are known to be alive; of these, seventeen are worse, four of them bed-ridden; nine report their conditions unchanged and eight report some improvement. We were

TABLE 2.-Etrologic Diseases

\begin{tabular}{|c|c|c|c|c|c|c|c|c|c|c|c|c|c|}
\hline 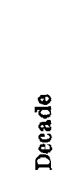 & 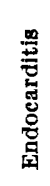 & 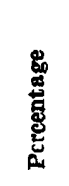 & 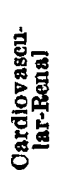 & 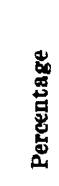 & 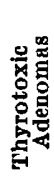 & 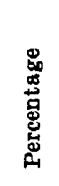 & 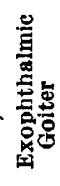 & 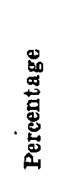 & 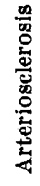 & 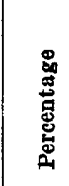 & 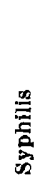 & 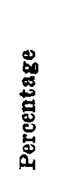 & 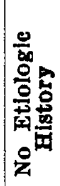 \\
\hline \multirow[t]{2}{*}{$\begin{array}{l}11-20 \\
21-30 \\
31-40 \\
\$ 1-50 \\
51-60 \\
61-70 \\
71-80\end{array}$} & $\begin{array}{r}2 \\
8 \\
5 \\
14 \\
10 \\
8 \\
2\end{array}$ & $\begin{array}{r}100.0 \\
80.0 \\
62.5 \\
45.2 \\
24.4 \\
20.5 \\
28.6\end{array}$ & $\begin{array}{r}0 \\
1 \\
0 \\
10 \\
14 \\
17 \\
2\end{array}$ & $\begin{array}{c}0 \\
10.0 \\
0 \\
32.3 \\
34.1 \\
43.6 \\
28.6\end{array}$ & $\begin{array}{l}0 \\
0 \\
0 \\
0 \\
6 \\
\mathbf{2} \\
\mathbf{1}\end{array}$ & $\begin{array}{r}0 \\
0 \\
0 \\
0 \\
14.6 \\
5.1 \\
14.2\end{array}$ & $\begin{array}{l}0 \\
1 \\
0 \\
1 \\
2 \\
1 \\
0\end{array}$ & $\begin{array}{c}0 \\
10.0 \\
0 \\
3.2 \\
4.8 \\
2.6 \\
0\end{array}$ & $\begin{array}{l}0 \\
0 \\
0 \\
0 \\
0 \\
2 \\
1\end{array}$ & $\begin{array}{r}0 \\
0 \\
0 \\
0 \\
0 \\
\mathbf{5 . 1} \\
\mathbf{1 4 . 2}\end{array}$ & $\begin{array}{l}0 \\
0 \\
\mathbf{1} \\
\mathbf{2} \\
\mathbf{1} \\
0 \\
0\end{array}$ & $\begin{array}{c}0 \\
0 \\
12.5 \\
6.5 \\
2.4 \\
0 \\
0\end{array}$ & $\begin{array}{l}0 \\
0 \\
2 \\
6 \\
9 \\
9 \\
1\end{array}$ \\
\hline & 49 & & 44 & & 9 & & 5 & & 3 & - & $4^{*}$ & & 27 \\
\hline
\end{tabular}

* Three cases under syphilis classifled under endocarditis.

TABLE 3.-T-Wave Negativity

\begin{tabular}{c|c|c|c|c|c|c|c}
\hline \hline Decades & $\begin{array}{c}\text { Lead } \\
1\end{array}$ & $\begin{array}{c}\text { Lead } \\
2\end{array}$ & $\begin{array}{c}\text { Lead } \\
\mathbf{3}\end{array}$ & $\begin{array}{r}\text { Leads } \\
\text { 1 and 2 }\end{array}$ & $\begin{array}{c}\text { Leads } \\
\mathbf{2} \text { and 3 }\end{array}$ & $\begin{array}{c}\text { Leads } \\
\mathbf{1 , 2} \text { and } 8\end{array}$ & Total \\
\hline $11-20$ & 1 & 0 & 0 & 0 & 0 & 0 & $\mathbf{1}$ \\
$21-30$ & 0 & 1 & 2 & 2 & 1 & 0 & 5 \\
$31-40$ & 1 & 0 & 3 & 1 & 0 & 0 & 5 \\
$41-50$ & 8 & 0 & 1 & 2 & 2 & 0 & 13 \\
$51-60$ & 14 & 0 & 3 & 3 & 6 & 1 & 27 \\
$61-70$ & 16 & 0 & 3 & 5 & 1 & 4 & 4 \\
$71-80$ & 2 & 0 & 0 & 1 & 1 & 0 \\
\hline & 42 & 1 & 12 & 14 & 11 & 5 & 85 \\
\hline
\end{tabular}

TABLE 4.-SUMMARY OF DEATHS

\begin{tabular}{|c|c|c|c|}
\hline & Decade & Total Cases & Deaths \\
\hline & 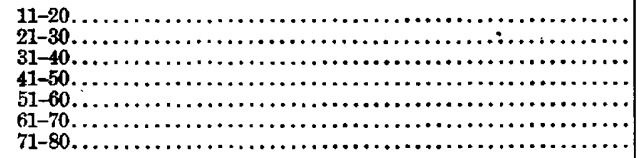 & $\begin{array}{r}2 \\
10 \\
8 \\
31 \\
41 \\
39 \\
7\end{array}$. & $\begin{array}{c}1 \\
3 \\
5 \\
16 \\
24 \\
23^{*} \dagger \\
6^{*}\end{array}$ \\
\hline & 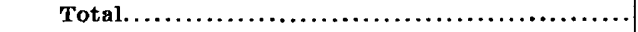 & 138 & 78 \\
\hline
\end{tabular}

* Died of cancer. $\quad+$ Died of pneumonia. 
afforded the opportminty of five necropsies; the cardiac findings are appended. No definite localizing lesions were found, but rather diffuse degenerative processes involving the myocardium.

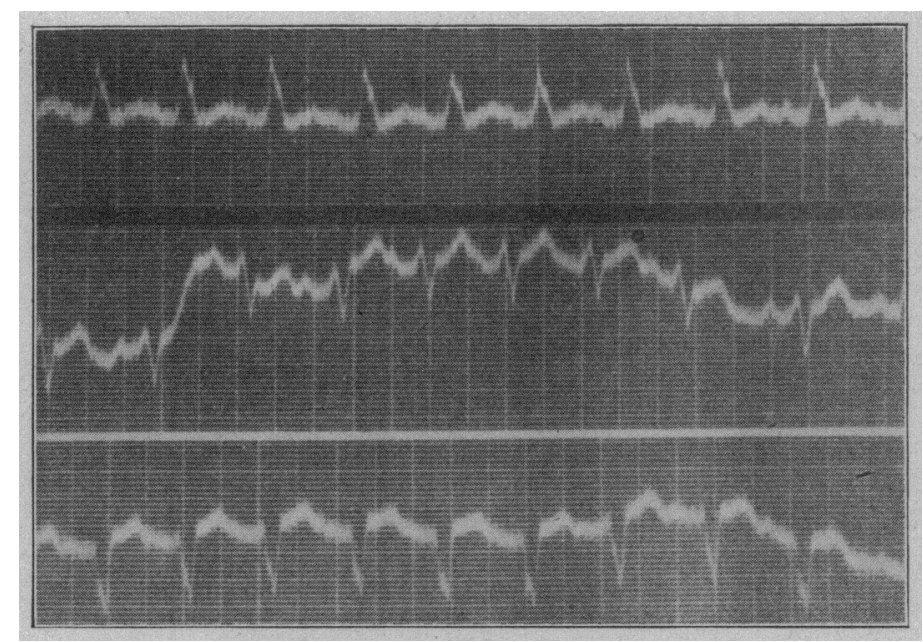

Fig. 5.-Rate 112. Q, R, S complex splintered and widened $0.12 \mathrm{sec}$. Left ventricular preponderance. Case 176302.

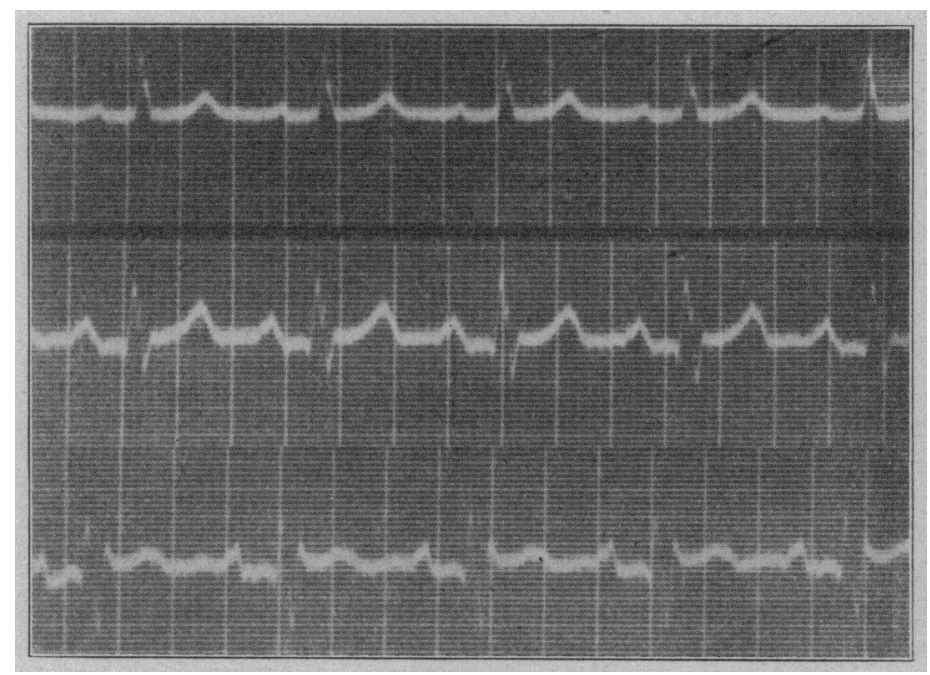

Fig. 6.-Rate 75. Q, R. S complex splintered $0.08 \mathrm{sec}$. Left ventriclular proponterance. Case 162663 .

CAs: 1 (130119).-Fery marked fatty changes in the myocardium: marked dilatation of the aortic mitral and tricuspid valuular rings of the heart: moderate nodular fibrous and fatty thickening of the lining of the aorta, and of the artic and mitral leaflets of the heart; marked thinning of the myo- 
carclium of the left rentricle; marked dilatation and engorgement of all of the chambers of the heart; moderate hydropericardium. Histologic Findings: Fragmentation and slight fatty changes.

CAsl: 2 (147045).--Obliterative fibrous adhesive pericarditis; marked nodular sclerssis and fatty changes in the lining of the aorta and its main

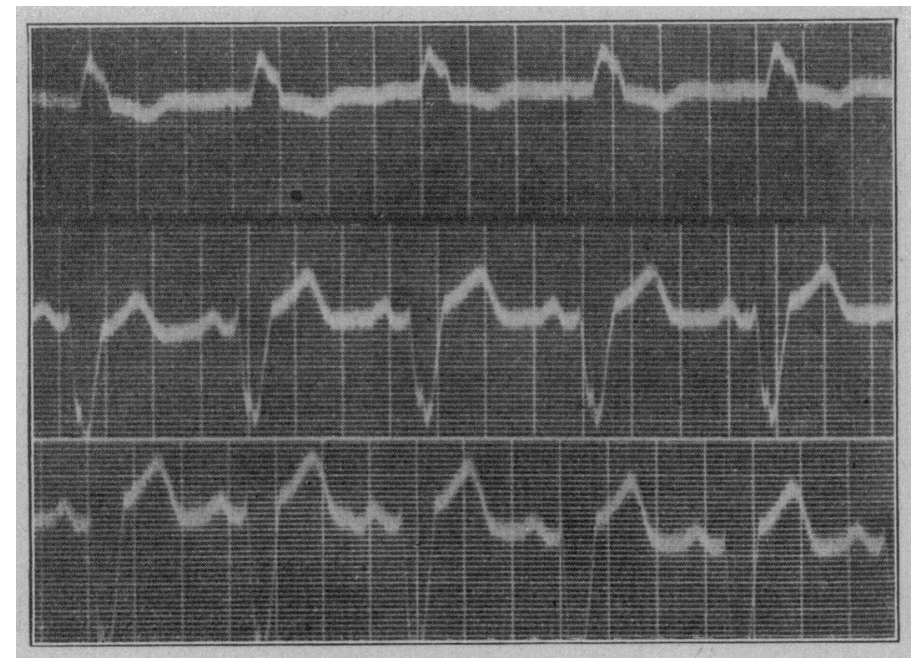

Fig. 7.-Rate 82. Q, R, S complex notched and widened $0.14 \mathrm{sec}$. Inverted T-wave, Lead 1. Left rentricular preponderance. Case 216281.

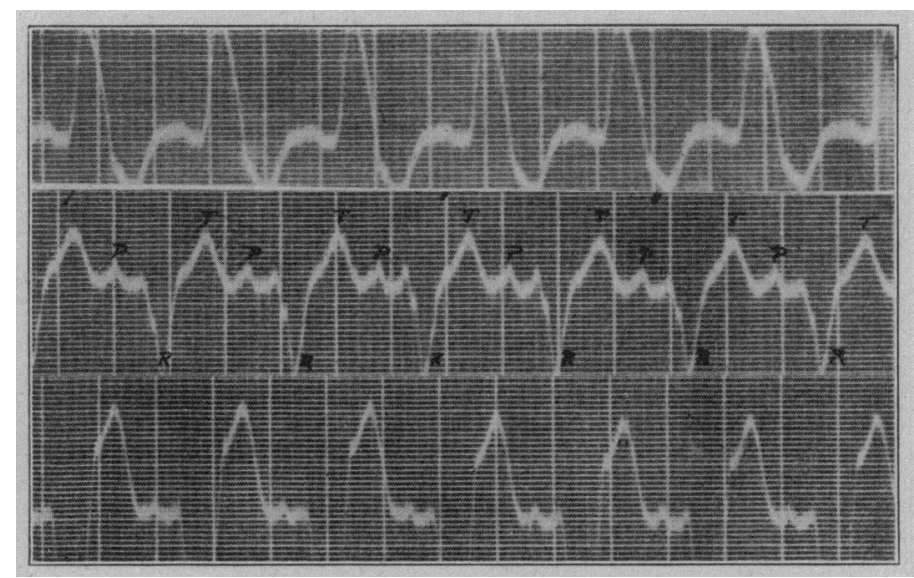

Fig. 8-Rate 115. Q, R, S complex splintered and widened 0.16 sec. Inverted T-wave Lead 1. Left ventricular preponderance. Case 143010.

branches: marked calcareous sclerosis of the cormary arteries; huge spontaneous thrombosis of the dependent portion of the left ventricle; marked hypertrophy of the myocardium of the left ventricle; marked dilatation of all the chambers of the heart: moderate dilatation of the aortic and mitral valvular rings; marked diffuse thickening of the pulmonary artery. Histologic Findings: 
The pericardium was thickened and adherent to the heart. There was a marked replacement of the heart muscle by fibrous tissue. Toward the lower portion was seen hyalinization of the muscle. The thrombus was made up of fibrin and in places showed a slight infiltration of leukocytes. With the fat stain considerable fat was found in the thrombus.

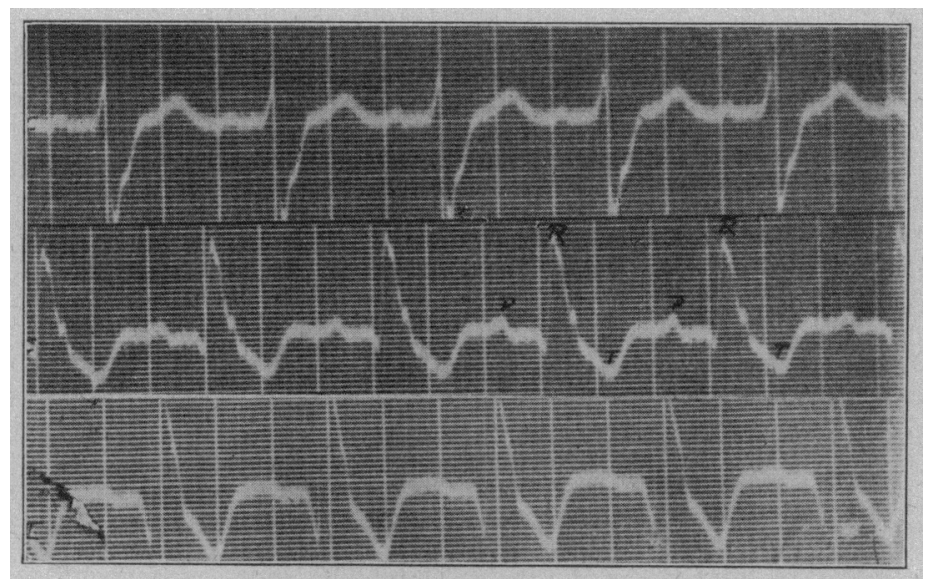

Fig. 9.-Rate 86. Q, R, S complex notched, splintered and widened 0.12 sec. Inverted T-wave, Leads 2 and 3. Right ventricular preponderance Case 142757.

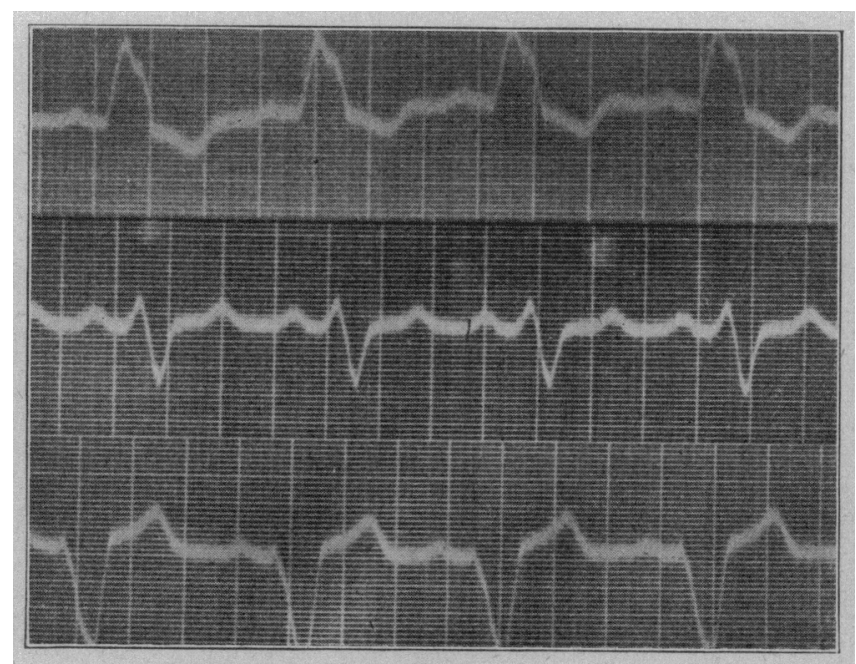

Fig. 10.-Rate 75. Q, R, S complex notched and widened 0.16 sec. Inverted T.-wave, Lead 1. Left ventricular preponderance. Case 154081.

CASE 3 (161776).-Marked fatty degeneration of the myocardium; marked hydropericardium; moderate dilatation of the heart. Histologic Findings: In the heart there were marked fatty degeneration and fragmentation; moderate increase in fil,rous connective tissue and hypertrophy of the muscle.

C.ASE 4 (189701).-Acute dilatation of the heart; marked fatty and fibrous sclerosis of the lining of the aorta and of the aortic and mitral valvular leaf- 
lets; petechial hemorrhages in the visceral pericardium. Histologic Findings: Moderate diffuse fatty degeneration of the myocardium. Aortitis probably luetic; fibrous and fatty changes in the intima and media, with round cell infiltration.

CASE 5 (197468).-Marked fatty and fibrous diffuse parenchymatous myocarditis; marked hypertrophy of the myocardium of the left ventricle; marked dilatation of all the chambers and valvular rings of the heart; spontaneous mural thrombosis of the left ventricle; slight hydropericardium. Histologic Findings: Fatty and fibrous degeneration of the myocardium.

\section{SUMMARY}

1. Arborization block is a grave disorder of the cardiac mechanism; it entails a large and early mortality (69.6 per cent.), in an average duration of eight and one-half months.

2. Disorders responsible for the development of this condition were found to be, in order of frequency, (1) infections, (2) degenerative processes, and (3) local nutritional disturbances.

3. The relative infrequency of edema was a striking observation.

4. The lack of definition and differentiation between the first and second heart sounds was constantly observed. 